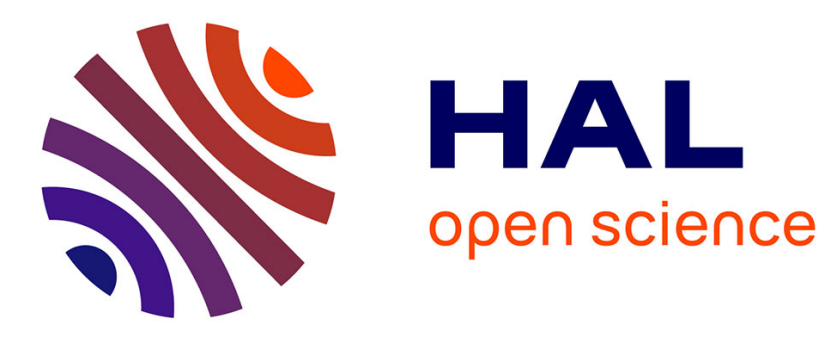

\title{
Manifested flatness defect prediction in cold rolling of thin strips
}

Rebecca Nakhoul, Pierre Montmitonnet, Nicolas Legrand

\section{To cite this version:}

Rebecca Nakhoul, Pierre Montmitonnet, Nicolas Legrand. Manifested flatness defect prediction in cold rolling of thin strips. International Journal of Material Forming, 2015, 8 (2), pp.283-292. 10.1007/s12289-014-1166-y . hal-00960137

\section{HAL Id: hal-00960137 \\ https://hal-mines-paristech.archives-ouvertes.fr/hal-00960137}

Submitted on 23 Dec 2015

HAL is a multi-disciplinary open access archive for the deposit and dissemination of scientific research documents, whether they are published or not. The documents may come from teaching and research institutions in France or abroad, or from public or private research centers.
L'archive ouverte pluridisciplinaire HAL, est destinée au dépôt et à la diffusion de documents scientifiques de niveau recherche, publiés ou non, émanant des établissements d'enseignement et de recherche français ou étrangers, des laboratoires publics ou privés. 


\section{Manifested flatness defect prediction in cold rolling of thin strips}

R. Nakhoul ${ }^{\mathrm{a}}$, P. Montmitonnet ${ }^{\mathrm{a}}$, N. Legrand ${ }^{\mathrm{b}}$

${ }^{a}$ CEMEF, MINES ParisTech, UMR CNRS 7635

Rue Claude Daunesse, CS 10207, 06904 Sophia-Antipolis, France,

Rebecca.nakhoul@mines-paristech.fr

Pierre.montmitonnet@mines-paristech.fr

b ArcelorMittal Research Maizières, R\&D Industrial Operations, Voie Romaine, BP 30320, 57283 Maizières-les-Metz, France

Nicolas.legrand@arcelormittal.com

\section{Corresponding author:}

Pierre MONTMITONNET,

MINES ParisTech CEMEF, CNRS UMR 7635,

Rue Claude Daunesse, CS 10207, 06904 Sophia-Antipolis Cedex, France

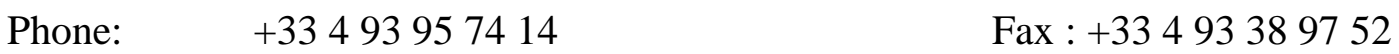

E-mail : $\quad$ pierre.montmitonnet@mines-paristech.fr 


\begin{abstract}
Flatness defects in thin strip cold rolling are a consequence of roll thermo-elastic deformation, from which heterogeneous strip plastic deformation results. When flatness defects manifest on line, buckling reorganizes the stress field in the pre- and post-bite areas. Comparison with flatness roll measurement requires this effect to be taken into account. A coupled Finite Element Method (FEM) approach is used here to compute stresses and strains in-bite as well as out-of-bite. The detection of buckled (non-flat) areas is demonstrated for a very thin strip cold rolling case (“double reduction”). The model is then applied here to two questions, namely the impact on flatness of the heterogeneous temperature field and the effect of friction on optimal setting of a flatness actuator, Work Roll Bending.
\end{abstract}

Keywords: Rolling; Thin Strips; Finite Element Method; Friction; Flatness Defect; Sheet Buckling; Residual Stress 


\section{INTRODUCTION}

In strip rolling, due to rolls elastic deformation combined with roll grinding crown, thermal crown and wear, the roll gap is not uniform in the width direction, so that strip reduction depends on the width coordinate $y$. Heterogeneous reduction induces residual stresses, and compressive residual stresses induce buckling (out of plane waviness) if the strip is thin hence easy to bend. Most of the time, the strip tension is high enough to keep the in-plane stress tensile everywhere and avoid buckling on-line. But once the strip tension is relaxed, or the sheet is cut, residual stresses may induce distortions called latent flatness defects, i.e. non developable, out-of-plane displacements forming periodic waves (centre waves, edge waves...).

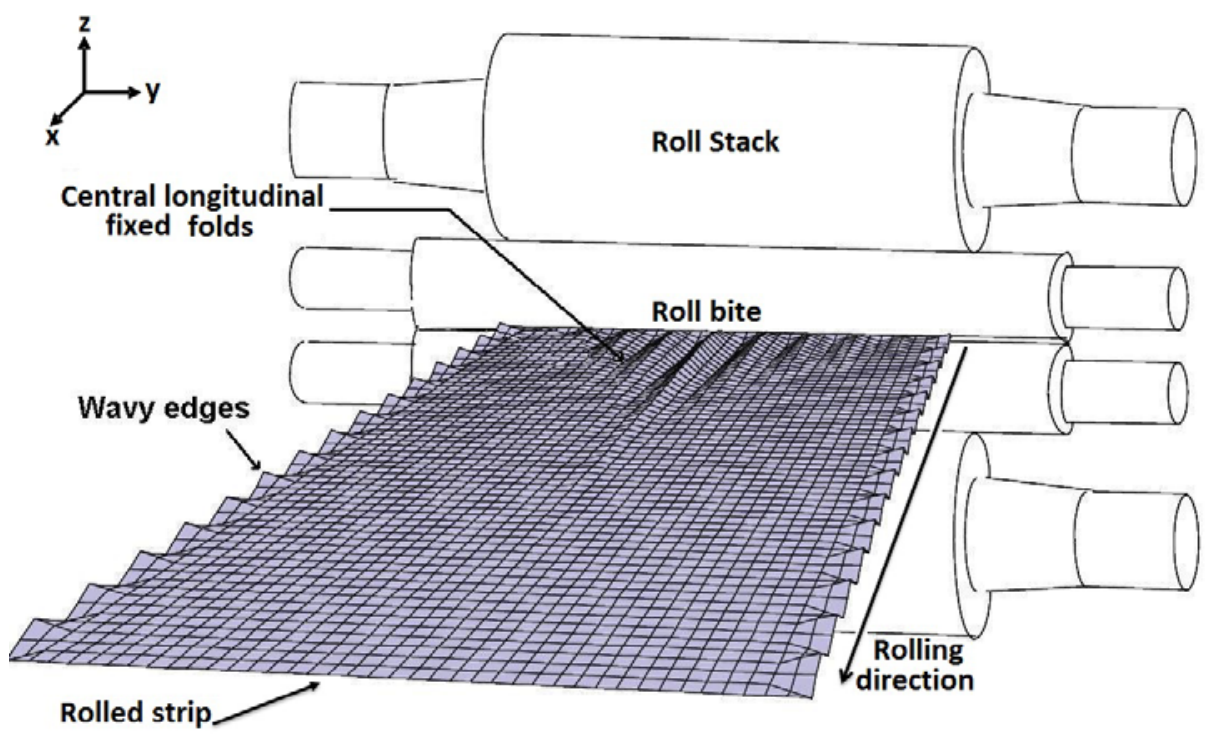

Fig. 1 Schematic view of flatness defects. Note reference frame $: x=$ Rolling Direction (RD), $\mathrm{y}=$ Transverse Direction (TD), $\mathrm{z}=$ Normal Direction (ND) 
However, in some severe operations such as thin strip cold rolling, strain and stress heterogeneity is exacerbated and on-line strip tension may be insufficient to prevent - or hide - waviness. In such a case, manifested flatness defects may show on-line (Fig. 1).

If defects are only latent, the stress field computed beyond the bite by e.g. a 3D FEM should be correct and consistent with measurements. Buckling upon unloading the strip tension can then be dealt with in an uncoupled way, transferring the stress pattern computed by the rolling model into a buckling model (e.g. shell FEM). The latter then tells if the critical conditions for buckling are met, and in this case computes post-buckling mode, wavelength and amplitude.

On the other hand, it is well known that buckling completely transforms stress fields since the local stiffness of a buckled sheet drops dramatically. Therefore, if defects are manifested online as is most of the time the case for very thin sheets, the solution coming out of the 3D FEM of rolling is completely irrelevant outside of the roll bite. Abdelkhalek et al. [1] have developed a fully coupled buckling model in an implicit finite element software devoted to rolling processes. They showed that it makes it possible to correct the out-of-bite stress fields and to come out with values consistent with the $\sigma_{\mathrm{xx}}(\mathrm{y})$ profile measurement by a flatness roll. The question of the impact of this stress reorganization on the strains and stresses within the bite has also been raised in the same paper. The conclusion is that to the possible exception of temper-rolling, the feedback effect is very small: the out-of-bite stress rearrangement is screened by the immediate bite exit area where complex velocity profile changes take place elastically. In the present paper, it is first recalled how the coupled buckling criterion detects buckled areas. Then applications to practical questions are examined, such as the setting of a flatness actuator (work roll bending), the effect of friction on the stress profile and on the “optimal” work roll bending setting, and the effect of a usual model simplification, isothermal versus thermally coupled. 


\section{BRIEF LITERATURE SURVEY}

A number of uncoupled models of flatness defects have been presented in the literature. They are based on the standard solution by Timoshenko and Woinovsky-Krieger of Von Karman's equations for a rectangular plate under compressive stress on simply supported edges. Timoshenko and Woinovsky-Krieger [2] assumed homogeneous stress and sinusoidal waves in both $\mathrm{x}$ and $\mathrm{y}$ directions. Bush et al. for instance [3] extended this solution to the complex fields of strip rolling, allowing only right/left symmetric waves. But as real waves are often anti-symmetric, Fischer and coworkers [4] chose for the transverse shape either an odd or an even polynomial in y, while keeping the waves sinusoidal in the rolling direction.

Only the longitudinal stress component $\left(\sigma_{\mathrm{xx}}\right)$ was used in these papers. Yet, it is easy to see that not all flatness defects can be handled with this assumption (herringbone defects for instance are excluded). Moreover, the type of defect (centre or edge wave) was determined by these authors a priori from the shape of the stress profile, and ad hoc clamping conditions were applied to get it in the end, to avoid managing too many modes with very similar energies. On the contrary, Yukawa and coworkers [5] addressed more complete configurations using shell FEM, again with a non-coupled approach. The bifurcation point was detected as the load parameter making the second variation of the total elastic strain energy (i.e. the stiffness matrix) non definite positive. Post-buckling was computed by introducing a small defect corresponding to the mode, the load step being controlled by a modified Riks method. This is the standard approach of instabilities in structural mechanics.

Abdelkhalek et al. [6] also proposed a decoupled approach, importing a FEM-computed stress field in a shell FEM for more generality. In the bifurcation detection stage, they maximized the load step and decreased the computational burden by managing the loading steps by the Asymptotic Numerical Method (ANM) developed initially by Zahrouni et al. [7] and 
improved by Boutyour et al. [8]. ANM consists in developing the solution (displacement and load parameter) in a power series with respect to a step length parameter, up to a truncation order $\mathrm{p}$. This series is inserted in the non linear equations of the problem, the different orders are identified, giving $\mathrm{p}$ linear systems with the same stiffness matrix, the right-hand sides of which are computed from the solutions at lower orders. With this approach, they modelled both on-line shape (under strip tension) and relaxed shape (strip tensions relieved), whereas the previous papers dealt only with the latter.

Counhaye [9] was the first who questioned the decoupling of the rolling and the buckling model. Indeed, buckling sets a limit to the allowable compressive stresses: wherever buckling occurs, the loss of rigidity changes the stress locally and global changes occur as the stress field is re-equilibrated. This thorough stress rearrangement on the one hand questions the stress fields obtained from the rolling models, on the other hand might have an impact even on in-bite stress and strain fields, or on roll deformation in strongly coupled cases. Therefore, Counhaye used an approach similar to the one proposed by Roddeman and coworkers [10], considering buckling as one more strain rate component, present only in the out-of-bite areas, to be added to the elastic / plastic strain rate splitting. This extra strain rate may be interpreted as the local shortening of a material segment as it becomes wavy due to buckling. The model presented in [1] and used here is an adaptation of Counhaye's model. 


\section{COUPLED ROLL - STRIP ROLLING MODEL WITH EMBEDDED BUCKLING}

The model has been presented in details elsewhere previously, so that only general lines will be recalled hereafter.

\subsection{Sheet Rolling model Lam3/Tec3}

The rolling model is Lam3/Tec3, a 3D strip / roll stack deformation software developed by Hacquin and coworkers [11]. The strip elastic-viscoplastic (EVP) deformation is dealt with by an implicit FEM with a velocity formulation using P1-discretisation on hexahedra. A steady state formulation based on streamlines is implemented. This requires integrating elasticviscoplastic constitutive equations along streamlines determined from the velocity field. In [12], they described the heterogeneous time step strategy used for this purpose, called ELDTH (Eulerian-Lagrangian with DT Heterogeneous). In [13], they focused on the semianalytical thermo-elastic roll deformation model. Inspired by the work of Berger et al. [14] on the deformation of a cylinder under complex loadings, Hacquin modelled the roll stack thermo-elastic deformation based on Timoshenko beam theory (bending component), Boussinesq solution of a half-space under general loading (flattening part), and Hertz contact mechanics between work rolls and back-up rolls. These analytical approaches were found insufficient near the roll barrel edge, therefore edge effects were corrected by analytical functions calibrated using an extensive FEM roll deformation campaign under various geometries and loading conditions $[11,13]$.

Equations are discretized by an influence function method (IFM). Writing the global equilibrium of the roll stack under the combined effects of the roll - strip contact stresses, external (roll load) and internal (e.g. roll bending) forces, a system of equations is found, the unknowns of which are the roll rigid body displacement, contact line displacement field and 
contact pressure profiles at work roll / back-up roll and work roll / strip contact. This system, non-linear due to unknown contact lines, is solved by Newton-Raphson method.

Both strip and roll temperatures are computed and coupled with mechanics. The strip temperature model uses a straightforward 3D SUPG (Streamline-Upwind Petrov Galerkin) Finite Element scheme. The roll temperature (and roll crown) model is a combination of 2D $(r, \theta)$ and $(r, z)$ FEM coordinated by another influence function technique. Details and validation can be found in [11].

In [15], the whole roll stack deformation model was validated under isothermal conditions against experimental measurements performed under diverse loading conditions. Later on in [16], a successful numerical comparison was carried out with the model of Yanagimoto and Kiuchi [17], which uses a beam bending model for roll bending and 3D FEM for flattening, and with the model of Kim et al. [18] where full 3D elastic FEM is used for roll stack deformation and strip deformation altogether; all three models were compared with the experiments reported by [17]. Therefore, this roll stack deformation model, essential for strip flatness, can be used with confidence for the purpose of the present paper.

\subsection{Simple buckling model embedded in Lam3/Tec3}

Counhaye’s model [9] has been implemented in Lam3/Tec3 [1]. Initially proposed within the membrane theory framework in [10], it forbids the appearance of a negative stress: everywhere compression is about to occur, the structure buckles, bringing the stress back to almost zero by providing a stress-free alternative to elastic shortening of a material line. The following critical conditions are introduced:

$$
\begin{aligned}
& \vec{n}_{1} \cdot \sigma \cdot \vec{n}_{1}=0 \\
& \vec{n}_{2} \cdot \sigma \cdot \vec{n}_{2}>0 \\
& \vec{n}_{1} \cdot \sigma \cdot \vec{n}_{2}=0
\end{aligned}
$$


where $\vec{n}_{1}$ and $\vec{n}_{2}$ are the principal directions of the Cauchy stress tensor $\sigma$ in the buckled structure (hence the third equation). Principal directions are determined first, and the angle they make with $(\mathrm{x}, \mathrm{y})$ is called $\alpha$. When a tension is applied in a direction (here $\vec{n}_{2}$ ), the membrane is stiff; if the stress becomes negative, it gets slack and in fact, the corresponding stress is put to 0 (direction $\vec{n}_{1}$ ). The essence of the model consists in determining an extra deformation which elastically brings the stress in the buckled direction back to 0 . It may be interpreted as the shortening of a material line due to buckling of the structure. This is more or less analogous to elastic-plastic decomposition, but is activated only out of the roll bite, i.e. where buckling is liable to occur:

$$
\Delta \varepsilon=\Delta \varepsilon^{e l}+\Delta \varepsilon^{b u}
$$

$\Delta \varepsilon^{e l}$ is the elastic and $\Delta \varepsilon^{b u}$ is the "buckling strain" increment. Plane stress is assumed outside of the roll bite. The extra deformation representing buckling is computed in the principal axes, and then transported to the reference frame. Let $\lambda_{\mathrm{i}}, \mathrm{i}=\mathrm{I}$, II, be the principal components of this extra strain. It is deduced from $\sigma_{\mathrm{i}}, \mathrm{i}=\mathrm{I}$, II as follows:

$$
\lambda_{i}=\frac{\left\langle\sigma_{i}-\sigma_{c}\right\rangle}{E} \quad i=I, I I
$$

Moving back to the reference frame $(O x y z)$, the buckling strain increment is added to the global strain increment. In the following equation, $\mathrm{u}$ and $\mathrm{v}$ are the two in-plane incremental 
displacements, $\alpha$ is the angle between principal and reference frames in the plane of the strip, $v$ is Poisson's ratio and $\mathrm{E}$ is Young's modulus:

$$
\begin{aligned}
& \Delta \varepsilon_{x x}=\frac{\partial u}{\partial x}+\lambda_{I} \cdot \cos ^{2} \alpha+\lambda_{I I} \cdot \sin ^{2} \alpha \\
& \Delta \varepsilon_{y y}=\frac{\partial v}{\partial y}+\lambda_{I I} \cdot \cos ^{2} \alpha+\lambda_{I} \cdot \sin ^{2} \alpha \\
& \Delta \varepsilon_{x y}=\frac{1}{2}\left(\frac{\partial u}{\partial x}+\frac{\partial v}{\partial y}\right)+\left|\lambda_{I I}-\lambda_{I}\right| \cos \alpha \cdot \sin \alpha \\
& \Delta \varepsilon_{z z}=-\frac{v}{1-v}\left(\Delta \varepsilon_{x x}+\Delta \varepsilon_{y y}\right)
\end{aligned}
$$

This strain increment replaces the standard one fed into the module which solves the constitutive differential equations.

\section{ROLLING OPERATION INVESTIGATED}

\subsection{Definition of rolls, material, strip dimensions}

All examples and parametric studies described hereafter refer to the same rolling pass, the last stand of a tinplate sheet mill, with very low thickness. All the characteristics are given in Table 1, together with the stress-strain curve:

$$
\sigma_{0}=(470.5+175.4 . \bar{\varepsilon}) \times(1-0.45 . \exp (-8.9 \bar{\varepsilon}))-175(\mathrm{MPa})
$$

$\sigma_{0}$ is the yield stress in tension, $\bar{\varepsilon}$ is the equivalent plastic strain. Coulomb friction is assumed, the friction coefficient is $\mu=0.03$ unless otherwise stated. 
Table 1 Characteristics of the rolling pass investigated

\begin{tabular}{|c|c|c|c|c|}
\hline Strip width & $855 \mathrm{~mm}$ & \multirow{16}{*}{ 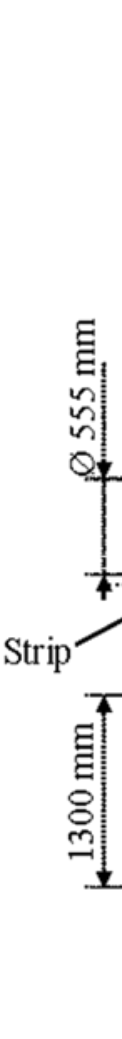 } & \multirow{2}{*}{$-700 \mathrm{~mm}$} & \multirow{8}{*}{ 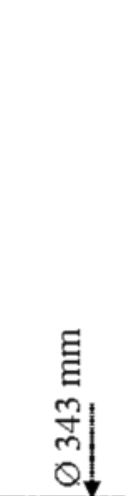 } \\
\hline $\begin{array}{l}\text { Strip thickness } \\
\text { (strip crown) }\end{array}$ & $\begin{array}{l}0.355 \mathrm{~mm} \\
(4.81 \%)\end{array}$ & & & \\
\hline Exit thickness & $0.252 \mathrm{~mm}$ & & \multirow{3}{*}{$645 \mathrm{~mm}$} & \\
\hline Rolling speed & $22 \mathrm{~m} / \mathrm{s}$ & & & \\
\hline $\begin{array}{l}\text { Front / } \\
\text { back tension }\end{array}$ & $\begin{array}{l}100 \mathrm{MPa} / \\
170 \mathrm{MPa}\end{array}$ & & & \\
\hline Type of mill & 4-high & & Back Up коI & \\
\hline Work rolls diameter & $555 \mathrm{~mm}$ & & & \\
\hline Backup rolls diameter & $1300 \mathrm{~mm}$ & & & \\
\hline Work rolls length & $1400 \mathrm{~mm}$ & & & -1 \\
\hline Backup rolls length & $1295 \mathrm{~mm}$ & & Work Roll & $\frac{1}{4}$ \\
\hline Work rolls crown & $0.0322 \%$ & & & \\
\hline Backup rolls crown & No crown & & & \\
\hline $\begin{array}{l}\text { Work roll bending } \\
\text { force / position }\end{array}$ & $\begin{array}{l}4.8 \mathrm{MN} / \\
\mathrm{y}=1010 \mathrm{~mm}\end{array}$ & & & 貊 \\
\hline $\begin{array}{l}\text { Screw force } \\
\text { application point }\end{array}$ & $\mathrm{y}=1075 \mathrm{~mm}$ & & & ฉ. \\
\hline Friction law & $\tau=0,03 \times \sigma_{n}$ & & & \\
\hline $\begin{array}{l}\text { Young's modulus } \\
\text { Poisson's ratio }\end{array}$ & $\begin{array}{l}\mathrm{E}=210 \mathrm{GPa} \\
\mathrm{v}=0.3\end{array}$ & & $1010 \mathrm{~mm}$ & \\
\hline
\end{tabular}

\subsection{Roll and strip deformation leading to buckling}

The roll load profile $\mathrm{F}(\mathrm{y})$ computed by the coupled roll / strip deformation model is pictured in Fig. 2a, together with the resulting shape of the deformed roll generator (Fig. 2b). By the way, Fig. 2b illustrates the very weak effect of coupling or not buckling on these in-bite characteristics.

The work roll shape displays a large flattening component, of the order of $0.07 \mathrm{~mm}$. The bending component shows outside the work roll / strip contact (i.e. y $>430 \mathrm{~mm}$ ), and is partly hidden in the contact area by flattening. The roll load profiles display distinct peaks near the edge of the strip for the work roll and at the edge of the work roll for the backup roll. The peak of the work roll load profile is explained by Fig. 3, which shows that the reduction, from a nominal, central $29 \%$, reaches $50 \%$ at the very edge of the strip, with a significantly longer bite. 


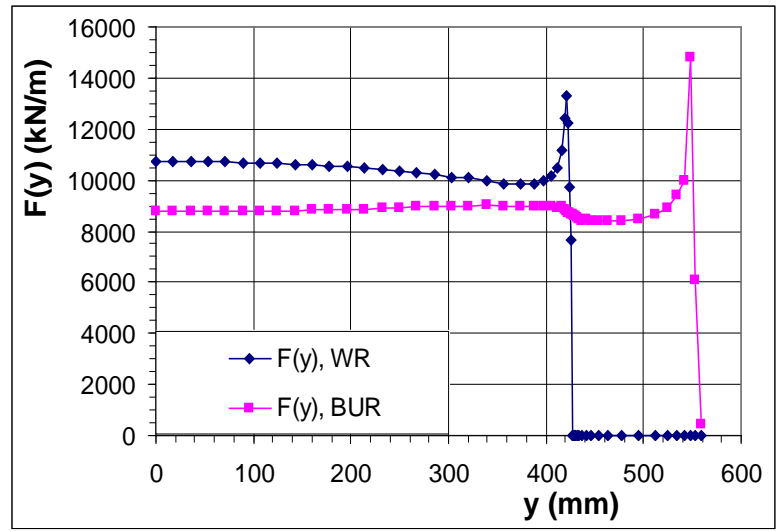

(a)

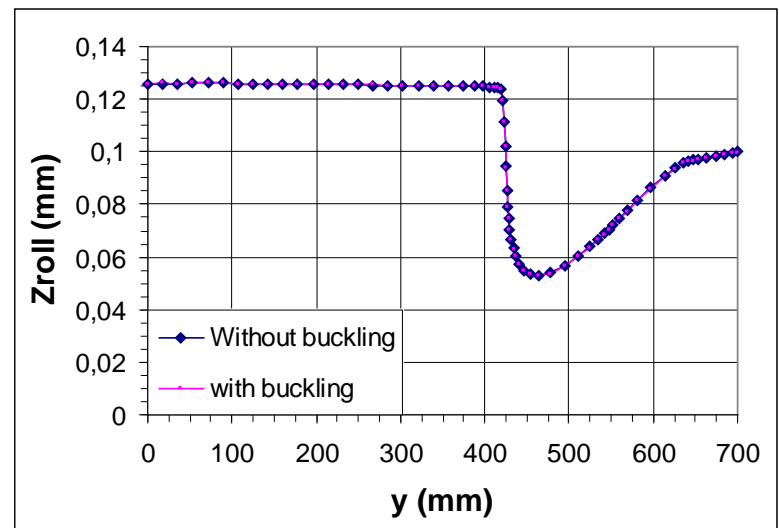

(b)

Fig. 2 Coupled deformation of strip and roll:

(a) work roll (WR) and backup roll (BUR) load profiles F(y)

(b) roll generator shape, comparing calculations with / without accounting for strip buckling

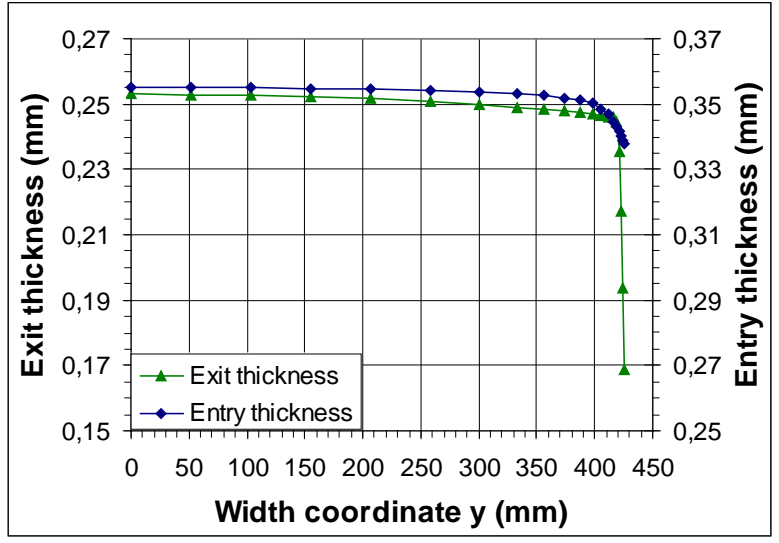

(a)

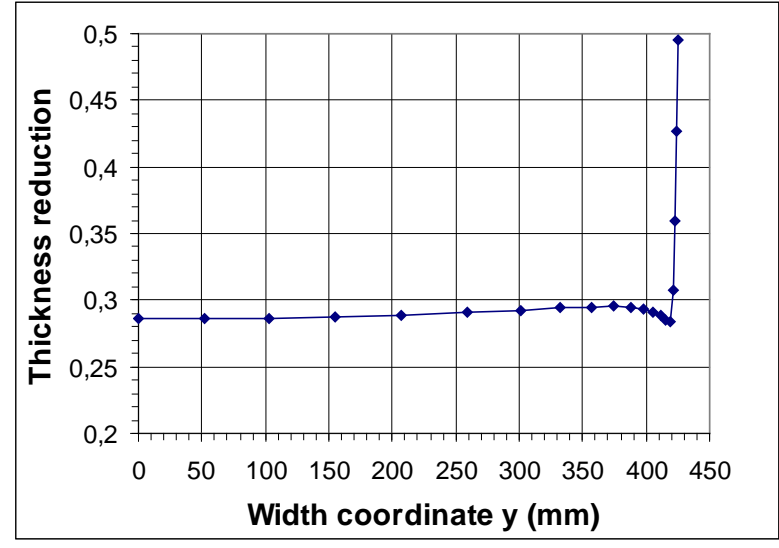

(b)

Fig. 3 Strain heterogeneity. (a) comparison of inlet and exit strip thickness profiles. (b) the thickness reduction profile

\subsection{Impact of buckling being accounted for}

With a reservation for very small reduction (temper-rolling), it has been found that this rearrangement of out-of-bite stress has significant impact neither on strain and stress fields in 
the bite, nor on the roll loads and deformation [1]. Neglecting buckling is therefore licit if only the behaviour in the bite is to be studied.

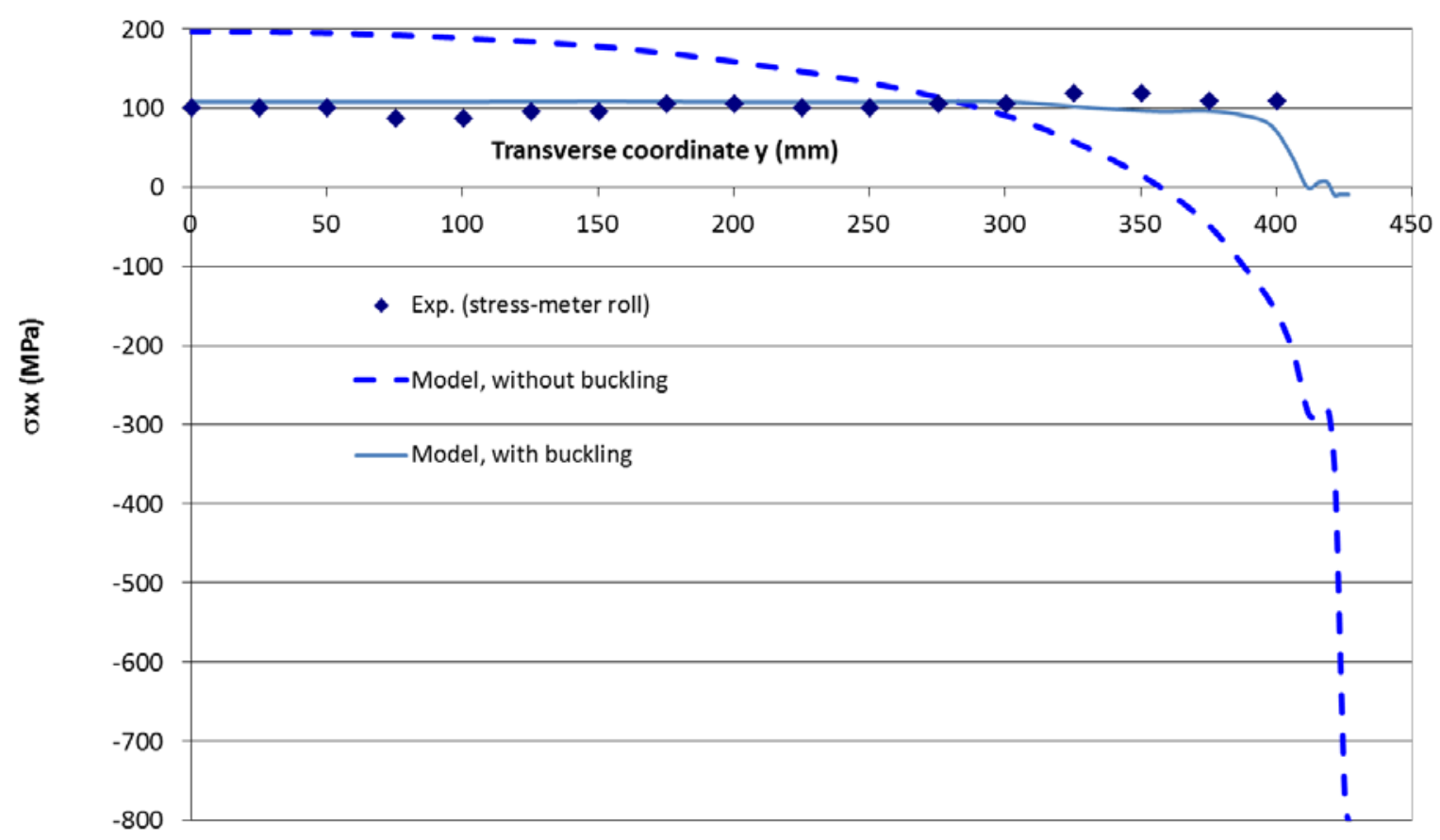

Fig. 4 Comparison of the experimental and numerical $\sigma_{\mathrm{xx}}(\mathrm{y})$ stress profiles, $\approx 1 \mathrm{~m}$ after roll bite exit

But the "residual" stress field in the strip, under these conditions, is very far from the flatness roll measurement, as shown in Fig. 4. "Residual” means here post-bite, on-line under tension. The measurements (dots) show an almost flat stress profile (at the scale of the drawing). FEM results without buckling (dashed line) give an enormous compressive stress at the edge, due to a very large elongation gradient connected with roll flattening and the edge drop defect (see Fig. 3). This very high compressive stress is compensated for by a high tensile stress in the centre, since the resultant must be equal to the sheet tension force (here given by the tension stress of $100 \mathrm{MPa}$, Table 1 ). Also to be noted is a stress peak at $\mathrm{y} \approx 415 \mathrm{~mm}$ (i.e. ca. $10 \mathrm{~mm}$ from strip edge). It is much more conspicuous when buckling relaxes partly the stress 
(as in figure 8 or 12); the same location and amplitude is found whatever the mesh size; it is in fact exactly at the location where the edge-drop starts, i.e. the transition between the flattened and free zones of the roll profile, see figure $2 \mathrm{~b}$.

When buckling is accounted for, i.e. equations (1-4) are activated, the computed stress profile (full line) comes close to the experiments. More details can be found in the authors' previous paper [1]. Therefore, for out-of-bite stress prediction and comparison with stress-meter measurements, accounting for buckling is essential, at least for thin strips.

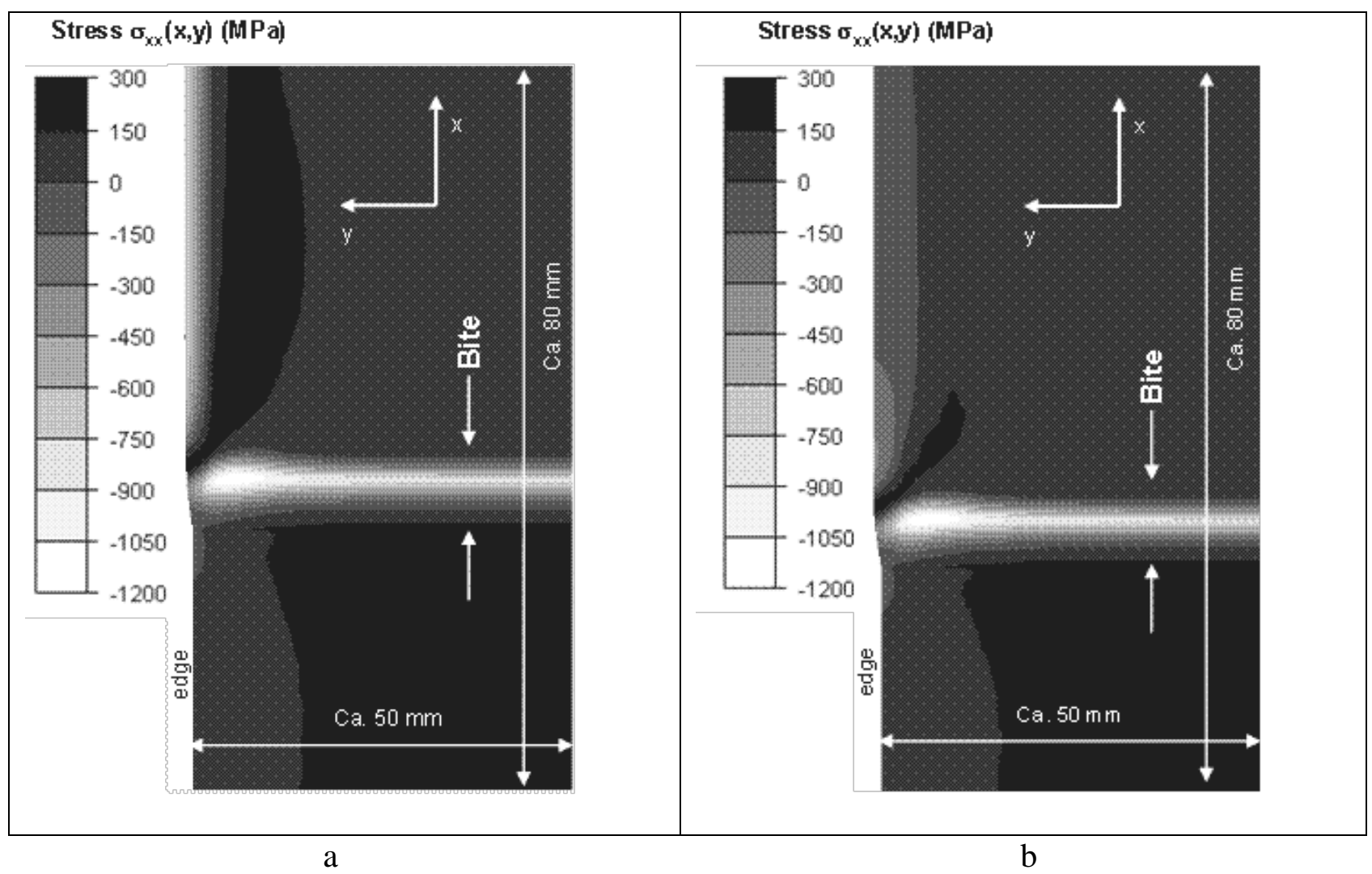

Fig. $5 \sigma_{\mathrm{xx}}$ stress maps at the edge, in the vicinity of the roll bite. a - without buckling computation. b - with buckling computation. Rolling direction Ox is vertical, upward.

Fig. 5 shows the $\sigma_{\mathrm{xx}}$ stress map at the edge, slightly before and slightly after the roll bite, i.e. far ahead of the location of the profiles of Fig. 4. It compares computations without (Fig. 5a) and with (Fig. 5b) the buckling model. The stress is very much compressive in the bite as 
expected. In the latter case, a thorough reorganization of the stress pattern just after bite exit results in the stress being relaxed to almost zero on the edge within $20-30 \mathrm{~mm}$ from bite exit, instead of dropping abruptly to $-1200 \mathrm{MPa}$.

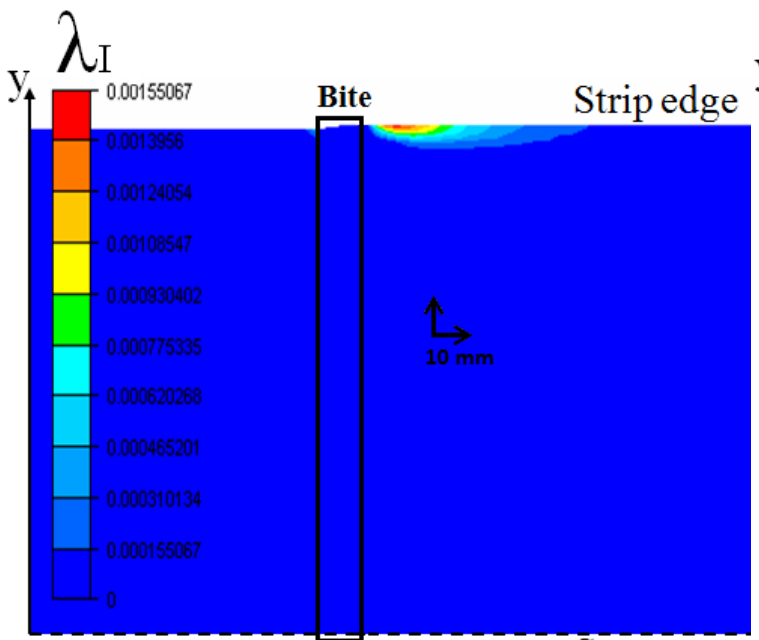

$\overrightarrow{\text { Rolling direction }}$
Symmetry

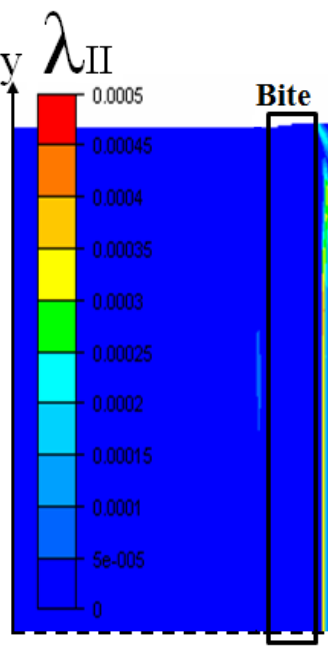

$\overrightarrow{\text { Rolling direction }}$ Strip edge

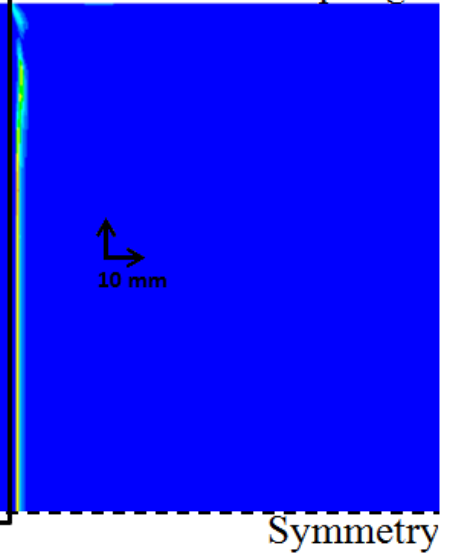

$\mathrm{b}$

Fig. 6 « Buckling strain » principal components: a - $\lambda_{\mathrm{I}}$ (corresponding to $\sigma_{\mathrm{xx}}$ stress); $\mathrm{b}-\lambda_{\mathrm{II}}$ (corresponding to a $\sigma_{\text {yy }}$ stress)

Fig. 6 maps the $\lambda_{\mathrm{i}}$ 's in the same area. It is found that the reference and principal stress frames coincide almost everywhere, i.e. $\alpha=0$, except for small high shear zones at the edge on either sides of the roll bite. Hence $\lambda_{\mathrm{I}} \neq 0$ corresponds to a $\mathrm{x}$-wave (wavy edge) and $\lambda_{\mathrm{II}} \neq 0$ to $\mathrm{y}$-wave, the so-called "towel effect". Whereas the former is moving with the strip and constitutes a real flatness defect, the latter is a stationary phenomenon which can be observed sometimes at the exit of the bite. It is due to a flexible membrane being submitted to a tension under a nonstrictly homogeneous tension stress (e.g. due to the clamping effect of the roll bite). It has no practical consequences for the strip most of the time, except if it becomes so large that double thickness rolling occurs; this improbable case is not addressed here. 
Both types of waves are detected by the model. It should be emphasized, though, that the present buckling model is embedded in a steady state rolling model, so that it represents a moving defect in a stationary context. It can therefore detect wave formation, but not characterize its geometry.

\section{FIRST APPLICATION: IMPACT OF TEMPERATURE FIELD ON FLATNESS}

Most of the time, thermal effects are neglected in steel cold rolling, and flatness defects are studied under isothermal conditions. Here, with all three couplings available: strip - roll, mechanical - thermal, and buckling, many effects may be investigated.

Indeed, at bite exit, the temperature is much larger at the edge than in the centre (Fig. 7), about $438 \mathrm{~K}\left(165^{\circ} \mathrm{C}\right)$ versus $383 \mathrm{~K}\left(110^{\circ} \mathrm{C}\right)$. This is due to larger reduction and plastic heating (see Fig. 3). Due to the corresponding differential dilatation, the post-bite stress pattern could be affected. A series of simulations has therefore been run, with roll temperature calculated at steady state (i.e. after a long rolling time). The isothermal case is taken as a reference. In the second case, the strip is allowed to cool after bite exit under the effect of the strip cooling system, with heat transfer coefficient (HTC) $\mathrm{H}_{\text {cool }}=5 \mathrm{~kW} \cdot \mathrm{m}^{-2} \cdot \mathrm{K}^{-1}$; strip - roll contact is kept adiabatic $\left(\mathrm{H}_{\text {roll }}=0\right)$. Temperature increases in the roll bite and slowly decays afterwards (remember $1 \mathrm{~m} \approx 0.05 \mathrm{~s}$ ). In the third case, the roll - strip interface is represented by $\mathrm{H}_{\text {roll }}=100 \mathrm{~kW} \cdot \mathrm{m}^{-2} \cdot \mathrm{K}^{-1}$. The temperature increase is less in the bite, cooling is similar to the previous case. Finally, in the fourth case, $\mathrm{H}_{\text {cool }}=5 \mathrm{~kW} \cdot \mathrm{m}^{-2} \cdot \mathrm{K}^{-1}, \mathrm{H}_{\text {roll }}=100$ $\mathrm{kW} \cdot \mathrm{m}^{-2} \cdot \mathrm{K}^{-1}$, but rolls are moreover cooled efficiently by water sprays, so that strip temperatures are significantly lower.

Yet, the temperature difference between strip edge and centre is very similar in all 3 cases, 313 to $323 \mathrm{~K}\left(40^{\circ} \mathrm{C}\right.$ to $\left.50^{\circ} \mathrm{C}\right)$. Fig. 8 shows that these temperature differences, even in the 
isothermal case $\left(\mathrm{T}=298 \mathrm{~K}\right.$ or $25^{\circ} \mathrm{C}$ everywhere), have negligible impact on the stress pattern once relaxed by edge buckling.
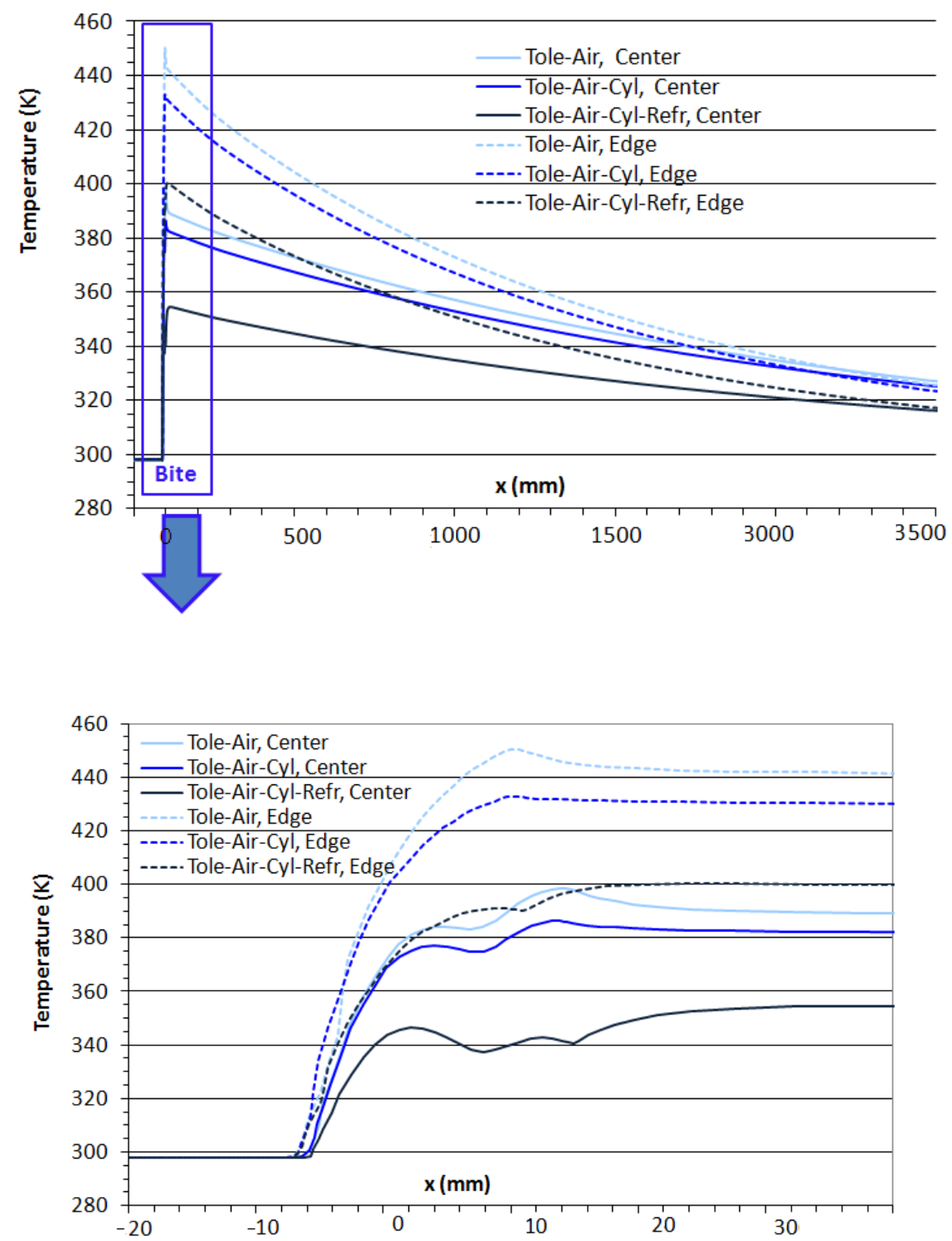

Fig. 7 Effect of thermal boundary conditions on central and edge longitudinal temperature profiles in the rolled strip. Top: long range post-bite evolution. Bottom: detail of plastic heating in the roll bite 


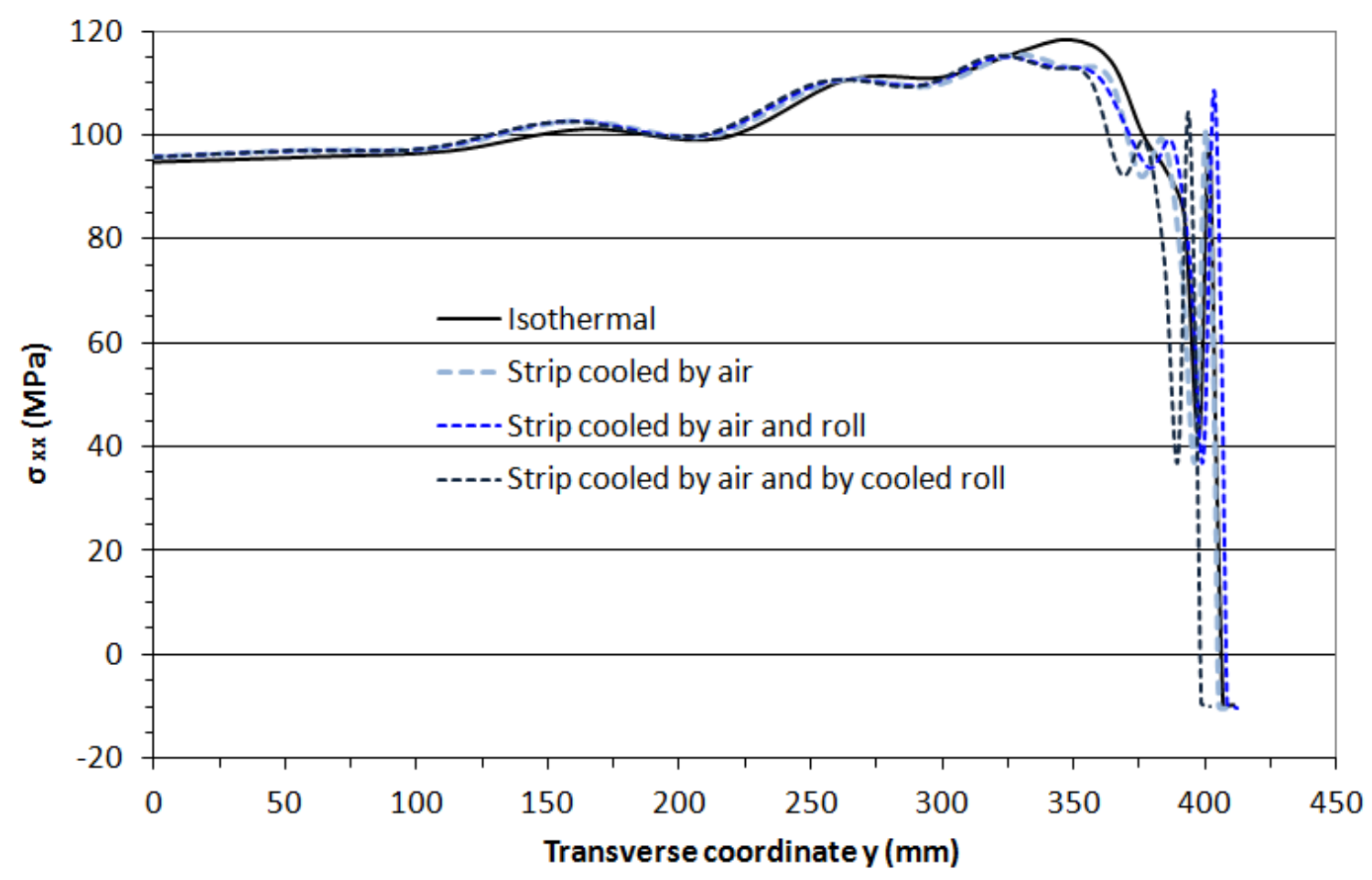

Fig. 8 Effect of all thermal boundary conditions on stress transverse profile, $\sigma_{\mathrm{xx}}(\mathrm{y})$

\section{FRICTION-SENSITIVE SETTING OF WORK ROLL BENDING FORCES}

Work roll bending is a typical sheet profile and flatness actuator: by applying a torque opposed to the contact stress moment, rolls are brought closer to their rest shape. This is a more flexible actuator than e.g. roll crown, which is chosen and fixed for a whole roll mounting. The work roll bending force can be controlled by monitoring the post-bite strip stress profile by a flatness roll, to answer variations in rolling conditions. Such variations often come from friction which may fluctuate due to (i) progressive roll roughness wear from coil to coil or (ii) accelerations and decelerations at coil beginning and end. Jiang and coworkers have proved in [19] that friction impacts strip profile after cold rolling and demonstrated the effect of a parabolic variation of friction in the transverse direction in [20]. It is therefore important to quantify the effects of such friction time variations. Friction is assumed homogeneous here. 


\subsection{Impact of friction on roll deformation}

Figs. 9-12 illustrate a parametric study whereby friction varies between $\mu=0.01$ (slight skidding) and $\mu=0.035$. The impact on roll deformation under a fixed work roll bending force of $482 \mathrm{kN}$ is first shown. Low friction gives a low rolling load (Fig. 9), and moderate roll deformation (Fig. 10). The shape of the work roll generator therefore mainly corresponds to counter-bending by the work roll bending force.

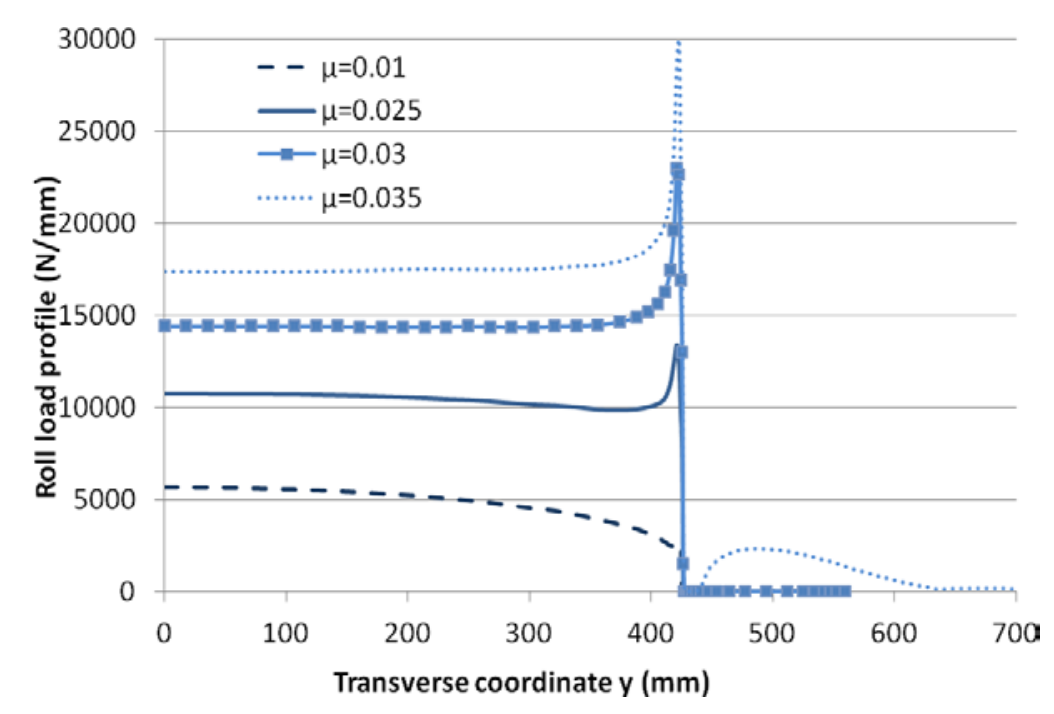

Fig. 9 Effect of varying friction on the work rolls load profile $F(y)$. Work roll bending force is equal to $482 \mathrm{kN}$

At $\mu=0.035$, the rolling load is very high (compare the work roll load profiles), so that roll kiss occurs (work rolls touch each other on either sides of the strip). The resulting strip thickness profiles show differences (a few $\mu \mathrm{m}$ ) which may look small, but are very important in terms of residual stress and flatness. The latter are pictured in Fig. 12: $\mu=0.01$ gives strong tension on edges and slack centre (wavy centre), whereas the stress profile is most flat when $\mu=0.03$, leaving just a few mm of slack metal near the edges, with a probable small size wavy edge there. 


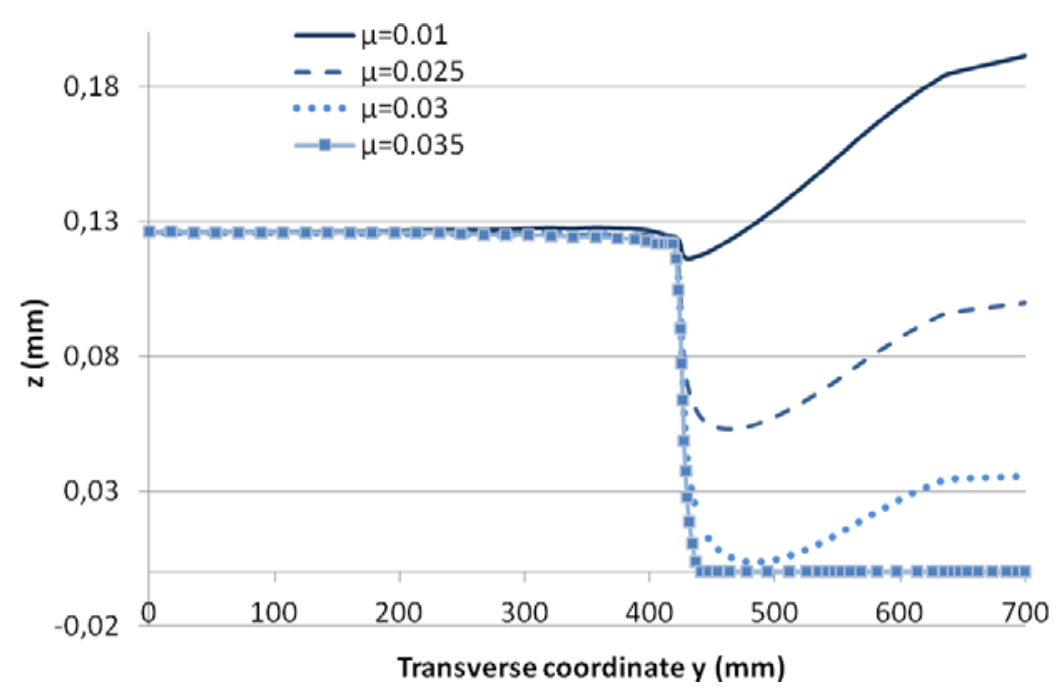

Fig. 10 Effect of varying friction on the deformed roll generator shape (bottom). Work roll bending force is equal to $482 \mathrm{kN}$

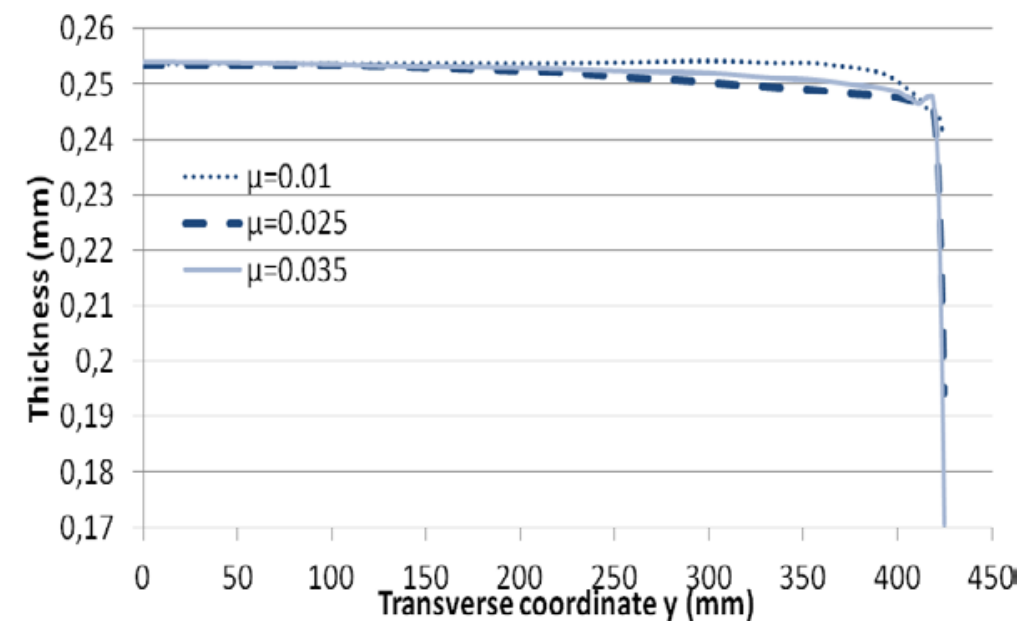

Fig. 11 Effect of varying friction on strip thickness profile (bottom). Work roll bending force is equal to $482 \mathrm{kN}$ 


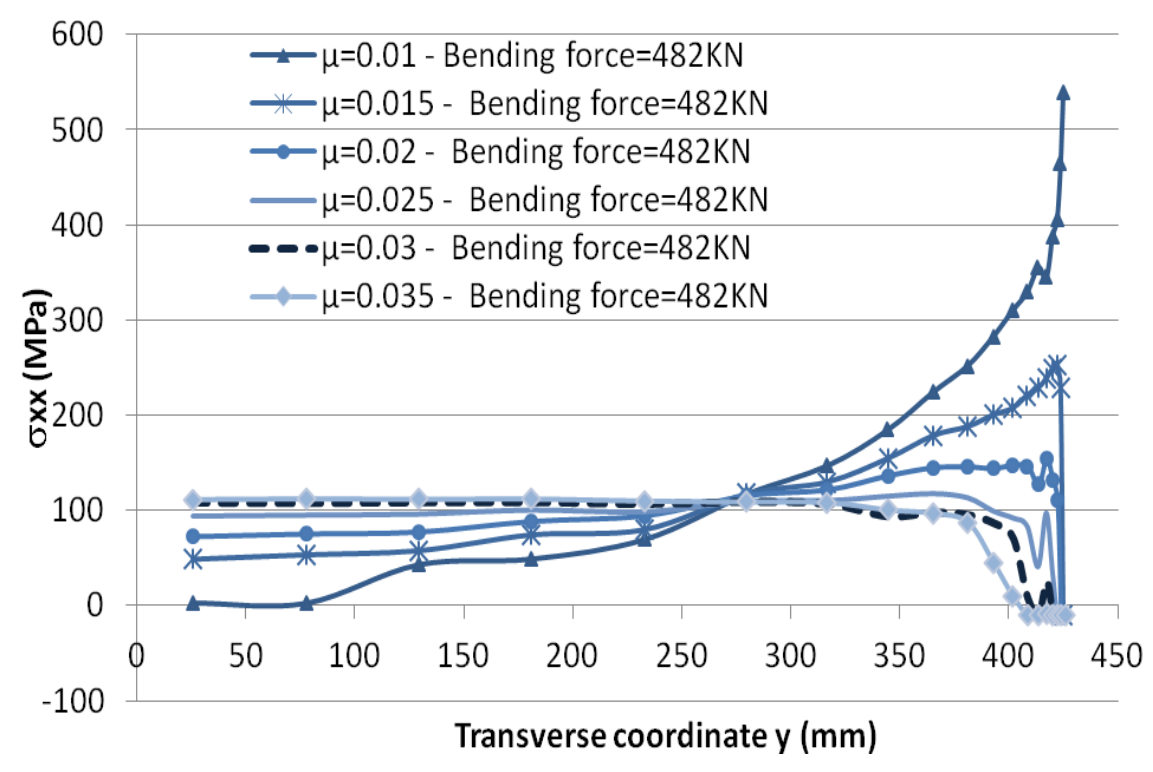

Fig. 12 The impact of friction and transverse profile of strip stress (latent flatness defect). Work roll bending force is equal to $482 \mathrm{kN}$

\subsection{Impact of work roll bending force at fixed $\mu$}

Now, the work roll bending force is varied at constant $\mu=0.025$ (Fig. 13). The very high work roll bending force (900 kN) again gives a low, yet positive, stress in the centre, which will probably result in a wavy centre, at least after tension is cancelled. The most flat stress profile turns out to be for a work roll bending force equal to $350 \mathrm{kN}$.

Finally, Fig. 14 summarizes the bending force found "optimal" for each value of the friction coefficient, i.e. giving the most flat stress profile "by eye”. This graph gives an idea of how to preset the work roll bending force as a function of varying friction, in the present rolling operation of Table 1. 


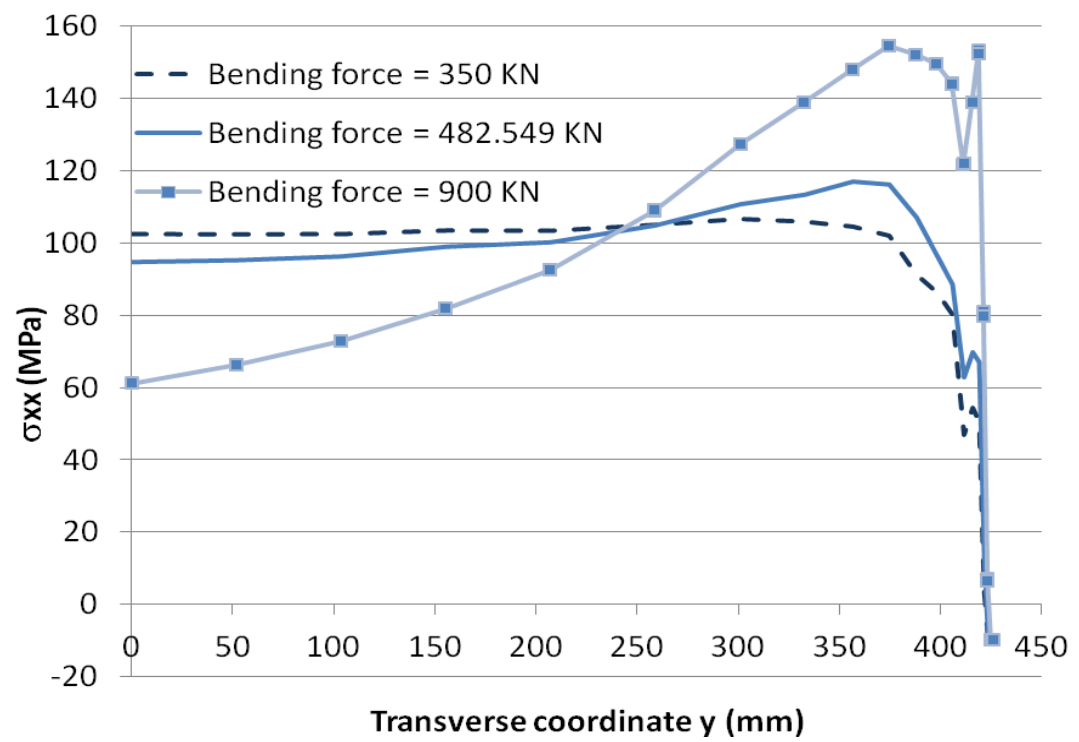

Fig. 13 The $\sigma_{\mathrm{xx}}(\mathrm{y})$ stress profile for varying bending force and fixed friction coefficient $\mu=$ 0.025

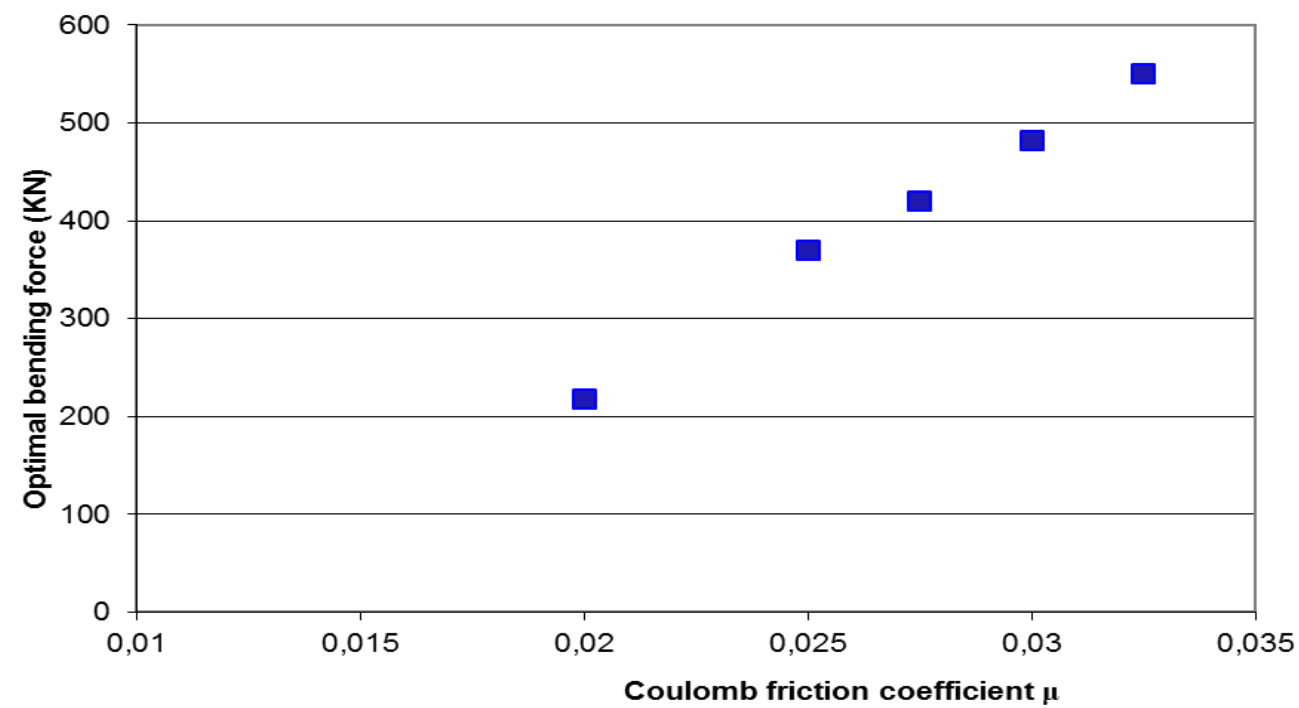

Fig. 14 The relationship between friction and optimal bending force 


\section{CONCLUSION}

The main outcome of the present paper is to show that a simple buckling model can be coupled to a finite element rolling model and applied to practical questions concerning flatness in cold strip rolling. In-bite stress and strain are not affected by post-buckling stress rearrangement, but the residual stress is, in case of manifested defects expected with very thin strips.

The results presented above suggest that for cold rolling, the heterogeneous temperature field does not change significantly the stress pattern, which is dominated by the rearrangement of the stress field as the elastic strain recovery takes place in the immediate post-bite area. This analysis contributes to shed light on which features of the rolling process may be neglected or not, depending on the objective: in bite stress and strain, roll deformation and strip crown do not need particularly buckling to be coupled; the residual state of the strip is very sensitive to buckling whenever it takes place on-line, but it is not sensitive to thermal transfer.

It has been shown also here that friction has an impact on reduction profile, in particular on the edge thickness, through roll load distribution and roll deformation. This strongly changes residual stress distribution when thin strips are dealt with. For a given work roll bending force, just changing friction may turn the strip shape from flat to wavy edge to wavy centre. Conversely, for each level of friction, an “optimal” work roll bending force can be proposed based on results of the model.

The buckling model presented in section 3.2 deals with buckling at material point (or finite element) level, which is questionable; but it is strongly coupled at constitutive equations level, which Abdelkhalek et al. have shown to be important for precise residual stress prediction [21]. It cannot predict the geometry of defects quantitatively. These are serious limitations. 
Work is in progress to try and implement more physically founded models which give quantitative information on defect geometry. These efforts will be reported somewhere else.

\section{ACKNOWLEDGEMENT}

The authors wish to thank the French National Research Agency (ANR) for its financial support under Contract ANR - 2010- RMNP-019-01, and the partners of the Platform Project (ArcelorMittal Maizières research, Constellium CRV, CNRS, CEA, Université de Lorraine, INSA Lyon and ARMINES) for authorization to publish this work. Particular thanks are due to M. Potier-Ferry and H. Zahrouni, from LEM3 laboratory, for most helpful discussions.

\section{REFERENCES}

1. Abdelkhalek S, Montmitonnet P, Legrand N, Buessler P (2011) Coupled approach for flatness predictions in thin strip cold rolling. Int. J. Mech. Sci. 53: 651-675

2. Timoshenko S, Woinovsky-Krieger S (1940) Theory of plates and shells, McGraw-Hill Book Co., New York

3. Bush A, Nicholls R, Tunstall J (2001) Stress levels for elastic buckling of rolled strip and plate. Ironm. Steelm. 28: 481-484

4. Fisher FD, Rammerstorfer FG, Friedl N, Wisser W (2000) Buckling phenomena related to rolling and levelling of sheet metal. Int. J. Mech. Sci. 42: 1887-1910

5. Yukawa N, Ishikawa T, Tozawa Y (1986) Numerical analysis of the shape of rolled strip. In: Proc. NUMIFORM Conference, August 25-29, Gothenburg, Sweden

6. Abdelkhalek S, Zahrouni H, Potier-Ferry M, Montmitonnet P, Legrand N, Buessler P (2009) Modélisation numérique du flambage des plaques minces et application au laminage. In : Proc. (CD-ROM) CFM 2009August 24-28, Marseille, France. In French 
7. Zahrouni H, Cochelin B, Potier-Ferry M (1999) Computing finite rotations of shells by an Asymptotic-Numerical Method. Comp. Meth. Appl. Mech. Engg 175: 71-85

8. Boutyour EH, Zahrouni H, Potier-Ferry M, Boudi M (2004) Bifurcation points and bifurcated branches by an Asymptotic Numerical Method and Padé approximants. Int. J. Num. Meth. Engg, 60: 1987-2012

9. C. Counhaye (2000) Modélisation et contrôle industriel de la géométrie des aciers laminés à froid. $\mathrm{PhD}$ Thesis, Liège University. In French

10. Roddeman DG, Drukker J, Oomens CWJ, Janssen JD (1987) The Wrinkling of Thin Membranes: Part I-Theory. ASME Trans. J. Appl. Mech. 54: 884-887

11. Hacquin A (1996) Modélisation thermomécanique tridimensionnelle du laminage Couplage bande / cylindres (3D thermomechanical model of rolling - Strip-roll coupling). PhD Thesis, Ecole des Mines de Paris, France. In French.

12. Hacquin A, Montmitonnet P, Guilleraut JP (1998) A steady state thermo-elastoviscoplastic finite element model of rolling with coupled thermo-elastic roll deformation. J. Mat. Proc. Tech. 60: 109-116

13. Hacquin A, Montmitonnet P, Guilleraut JP (1998) A 3D semi-analytical model of rolling stand deformation with finite element validation. Eur. J. Mech. A (Solids) 17: 79-106

14. Berger B, Pawelski O, Funke B (1976) Die elastische Verformung der Walzen von Vierwalzengerüsten. Arch. Eisenhüttenwes. 47: 351-356. In German

15. Hacquin A, Montmitonnet P, Guillerault JP (1994) Experimental validation of a Rolling Stand Elastic Deformation Model, J. Mater. Process. Technol. 45: 199-206

16. Montmitonnet P (2006) Comparison of profile prediction models for strip rolling, Conference “Achieving Profile \& Flatness in Flat Products” Austin Court, Birmingham, UK 
17. J. Yanagimoto, M. Kiuchi : 3D simulation system for coupled elastic / rigid plastic deformation of rolls and workpieces in strip rolling processes. Proc. NUMIFORM 92 (Sophia-Antipolis, France, 1992). J.L. Chenot et al. eds. A.A. Balkema, Rotterdam (1992)

18. T.H. Kim, W.H. Lee, S.M. Hwang : An integrated FE process model for the prediction of strip profile in flat rolling. ISIJ Int. 43, 12 (2003) 1947-1956

19. Jiang ZY, Tieu AK, Zhang XM, Lu C, Sun WH (2003) Finite element simulation of cold rolling of thin strip. J. Mat. Proc. Tech. 140: 542-547

20. Jiang ZY, Xiong SW, Tieu AK, Wang QJ (2008) Modelling of the effect of friction on cold strip rolling. J. Mat. Proc. Tech. 201: 85-90

21. Abdelkhalek S, Zahrouni H, Montmitonnet P, Legrand N, Potier-Ferry M (2011) Manifested flatness predictions in thin strip cold rolling using a general rolling FEM model, Steel Res. Int., Sp. Iss. “ICTP 2011” :111-116 


\section{Figure captions}

Fig. 1 Schematic view of flatness defects. Note reference frame : $\mathrm{x}=$ Rolling Direction (RD), $\mathrm{y}=$ Transverse Direction (TD), $\mathrm{z}=$ Normal Direction (ND)

Fig. 2 Coupled deformation of strip and roll:

(a) work roll (WR) and backup roll (BUR) load profiles F(y),

(b) roll generator shape, comparing calculations with / without accounting for strip buckling

Fig. 3 Strain heterogeneity. (a) comparison of inlet and exit strip thickness profiles. (b) the thickness reduction profile

Fig. 4 Comparison of the experimental and numerical $\sigma_{\mathrm{xx}}(\mathrm{y})$ stress profiles, $\approx 1 \mathrm{~m}$ after roll bite exit

Fig. $5 \sigma_{\mathrm{xx}}$ stress maps at the edge, in the vicinity of the roll bite. a - without buckling computation. b - with buckling computation. Rolling direction Ox is vertical, upward.

Fig. 6 «Buckling strain » principal components: $a-\lambda_{\mathrm{I}}$ (corresponding to $\sigma_{\mathrm{xx}}$ stress); $\mathrm{b}$ - $\lambda_{\text {II }}$ (corresponding to a $\sigma_{\mathrm{yy}}$ stress)

Fig. 7 Effect of thermal boundary conditions on central and edge longitudinal temperature profiles in the rolled strip. Left: long range post-bite evolution. Right: detail of plastic heating in the roll bite

Fig. 8 Effect of all thermal boundary conditions on RD stress transverse profile, $\sigma_{\mathrm{xx}}(\mathrm{y})$.

Fig. 9 Effect of varying friction on the work rolls load profile $\mathrm{F}(\mathrm{y})$. Work roll bending force is equal to $482 \mathrm{kN}$

Fig. 10 Effect of varying friction on the deformed roll generator shape (bottom). Work roll bending force is equal to $482 \mathrm{kN}$ 
Fig. 11 Effect of varying friction on strip thickness profile (bottom). Work roll bending force is equal to $482 \mathrm{kN}$

Fig. 12 The impact of friction and transverse profile of strip stress (latent flatness defect). Work roll bending force is equal to $482 \mathrm{kN}$

Fig. 13 The $\sigma_{\mathrm{xx}}(\mathrm{y})$ stress profile for varying bending force and fixed $\left.\mu=0.025\right)$

Fig. 14 The relationship between friction and optimal bending force

\section{Table caption}

Table 1 Characteristics of the rolling pass investigated 